\title{
CCXLIX. ADRENALINE AND AMINE OXIDASE
}

\author{
BY DEREK RICHTER ${ }^{1}$ \\ From the Biochemical Laboratory, Cambridge
}

(Received 29 September 1937)

BLASCHKo et al. $[1937,1]$ have shown that there is present in liver, intestine and other mammalian tissues an enzyme which catalyses the oxidation of adrenaline. For each molecule of adrenaline oxidized one atom of oxygen is taken up.

It has now been found that the products of this reaction are methylamine and an aldehyde; the reaction is an oxidative demethylamination and may be represented by the equation

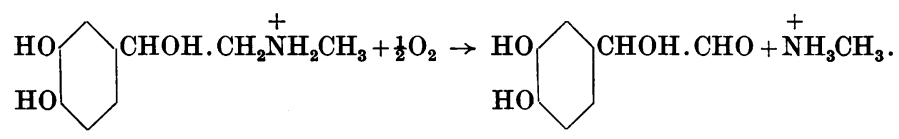

This reaction is chemically similar to the oxidative deamination of tyramine which is known also to be catalysed by an enzyme present in liver [Hare, 1928; Bernheim, 1931].

Blaschko et al. [1937, 2] found that a number of other primary and secondary amines are oxidized by liver extracts, and Pugh \& Quastel [1937] have recently described the oxidation of a further series of aliphatic amines. In the present paper is described the chemical investigation of the enzymic oxidation of a number of amines of different types. It was found that in each case the reaction products were an aldehyde and ammonia or a lower amine.

\section{Enzyme preparations}

(a) A very active enzyme preparation was obtained from guinea-pig liver as follows: $10 \mathrm{~g}$. liver were ground for $20 \mathrm{~min}$. with sand, $10 \mathrm{ml}$. $M / 15$ phosphate buffer $p \mathrm{H} 7 \cdot 3$ were added, the mixture was centrifuged and the supernatant fine suspension dialysed for $5 \mathrm{hr}$. To the dialysed suspension were now added $1.3 \mathrm{ml}$. $M$ phosphate buffer $p H \mathbf{H} 7.3$ and the mixture was made up to $20 \mathrm{ml}$. This enzyme preparation showed only a very low spontaneous oxygen uptake at $37^{\circ}$ and could be kept in the ice chest for several days.

(b) In a number of experiments a preparation from guinea-pig intestine was used. The intestine was slit open along its length, washed with water and disinfected by keeping for $10 \mathrm{~min}$. in 1/10,000 8-hydroxyquinoline solution. $10 \mathrm{~g}$. intestine were ground with sand for 20 min. mixed with $20 \mathrm{ml} . M / 15$ phosphate buffer $p \mathrm{H} \mathrm{7 \cdot 3}$ and the mixture centrifuged. The supernatant suspension contained an active enzyme but retained its activity for little more than a day.

The oxidations were carried out by shaking a mixture containing $1.9 \mathrm{ml}$. enzyme suspension and $0.2 \mathrm{ml}$. amine hydrochloride $(M / 4)$ in air in a Warburg apparatus at $37^{\circ}$. The liver preparations were used for all the experiments described; the intestine preparations were used for confirmatory experiments.

\footnotetext{
1 Beit Memorial Research Fellow.
} 


\section{Identification of ammonia and volatile amines}

Ammonia was liberated from the reaction products by treatment with an equal vol. of saturated $\mathrm{K}_{2} \mathrm{CO}_{3}$ in a Conway dish [Conway, 1933]. It was then converted into $(a)$ the picrate and $(b)$ the 2:4-dinitro- $\alpha$-naphthol derivative by introducing about $0.05 \mathrm{mg}$. of the reagent suspended in a drop of water on a coverslip attached by vaseline to the lid of the Conway dish. For identifying the volatile amines, traces of ammonia coming from the enzyme preparation were first removed by keeping the solution with an equal vol. of saturated $\mathrm{K}_{2} \mathrm{CO}_{3}$ for 45 min. at $37^{\circ}$ in a Conway dish containing dil. $\mathrm{H}_{2} \mathrm{SO}_{4}$ in the central compartment. In this time $99.5 \%$ of the ammonia but only a much smaller fraction of the volatile amines passed over into the acid. The residual amine was then converted into the derivatives $(a)$ and $(b)$ as with ammonia and the derivatives were identified by examining the optical properties of the crystals with the polarizing microscope in plane and polarized light [Klein \& Steiner, 1928]. In many cases the derivatives were recrystallized on the coverslips in order to obtain welldefined crystals.

By means of the two derivatives described it was possible to identify small quantities of amines of the order of $0.01 \mathrm{mg}$. very rapidly and with a high degree of certainty. The following properties, some of which were previously given by Klein \& Steiner [1928], were found particularly suitable for identifying amines in this way:

\begin{tabular}{|c|c|c|c|c|c|}
\hline r & Reagent & Ammonia & Methylamine & Dimethylamine & Ethylamine \\
\hline \multicolumn{6}{|c|}{ Picrates } \\
\hline Habit & Prisms & $\begin{array}{l}\text { Plates and } \\
\text { prisms }\end{array}$ & Plates & Plates & $\begin{array}{l}\text { Plates and } \\
\text { prisms }\end{array}$ \\
\hline Pleochroism & Weak & Distinct & Strong & Weak & Strong \\
\hline Extinction & Parallel & Parallel & Parallel & $42^{\circ}$ & Parallel \\
\hline Interference & Medium & Strong & Strong & Strong & Very strong \\
\hline $\begin{array}{l}\text { Crystal edge } \\
\text { angles }\end{array}$ & $\alpha=137^{\circ}$ & $\alpha=117^{\circ}$ & $\begin{array}{l}\alpha=129^{\circ} \\
\beta=141^{\circ} \\
\gamma=102^{\circ} \\
\delta=78^{\circ}\end{array}$ & $\begin{array}{l}\alpha=96^{\circ} \\
\beta=132^{\circ}\end{array}$ & $\alpha=123^{\circ}$ \\
\hline \multicolumn{6}{|c|}{ 2:4-Dinitronaphthol derivatives } \\
\hline Habit & Prisms & $\begin{array}{l}\text { Fine pointed } \\
\text { needles }\end{array}$ & $\begin{array}{l}\text { Blunt ended } \\
\text { prisms, often } \\
\text { curved }\end{array}$ & $\begin{array}{l}\text { Short prisms } \\
\text { square ended }\end{array}$ & Plates \\
\hline Pleochroism & Weak & Weak & Yellow-brown & $\begin{array}{l}\text { Marked yel- } \\
\text { low-brown }\end{array}$ & Weak \\
\hline Extinction & $0-10^{\circ}$ & Angular & Parallel & $20^{\circ}$ & Angular \\
\hline
\end{tabular}

Ammonia or volatile amines from the following series of amines were identified:

Phenylethylamine: $\mathrm{C}_{6} \mathrm{H}_{5} \mathrm{CH}_{2} \mathrm{CH}_{2} \mathrm{NH}_{2}$. Ammonia identified as above. Ammonium picrate gave $\alpha=117^{\circ}$. Found: $116^{\circ}$.

Tyramine: (HO) $\mathrm{C}_{6} \mathrm{H}_{4} \mathrm{CH}_{2} \mathrm{CH}_{2} \mathrm{NH}_{2}$. Ammonia identified.

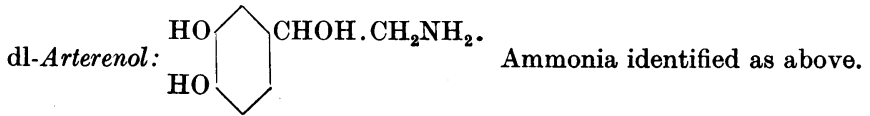

1-Adrenaline: ${ }_{\mathrm{HO}}^{\mathrm{HO}} \mathrm{CHOH} \cdot \mathrm{CH}_{2} \mathrm{NH} \cdot \mathrm{CH}_{3}$. Methylamine identified by dinitronaphthol

derivative and picrate crystals. Methylamine picrate gave $\alpha=129^{\circ}$. Found: $\alpha=129^{\circ}$. 
Epinine:

l-p-Sympatol:

dl-Alkamine: ${ }_{\mathrm{HO}}^{\mathrm{HO}} \mathrm{CHOH} \cdot \mathrm{CH}_{2} \mathrm{NH} \cdot \mathrm{C}_{2} \mathrm{H}_{5}$. Ethylamine identified by characteristic smell, isonitrile reaction and dinitronaphthol derivative.

Hordenine:

(dimethylamine gave extinction angle $20^{\circ} ; \alpha=105^{\circ} ; \beta=154^{\circ}$. Found: extinction angle, $21^{\circ}$; $\alpha=105^{\circ} ; \beta=155^{\circ}$ ). Picrate (dimethylamine picrate gave extinction $42^{\circ} ; \alpha=95^{\circ} ; \beta=131^{\circ}$ ). Found: extinction, $42^{\circ} ; \alpha=96^{\circ} ; \beta=132^{\circ}$.

The quaternary salt $N$-methylhordenine chloride was not oxidized.

\section{Quantitative estimation of ammonia and volatile amines}

For a few of the substrates the ammonia or volatile amines formed were estimated quantitatively by the Conway method (using similar conditions to those used by Conway [1933] for the estimation of ammonia). The rates of absorption of a number of different types of amines under standard conditions were first measured (Fig. 1).
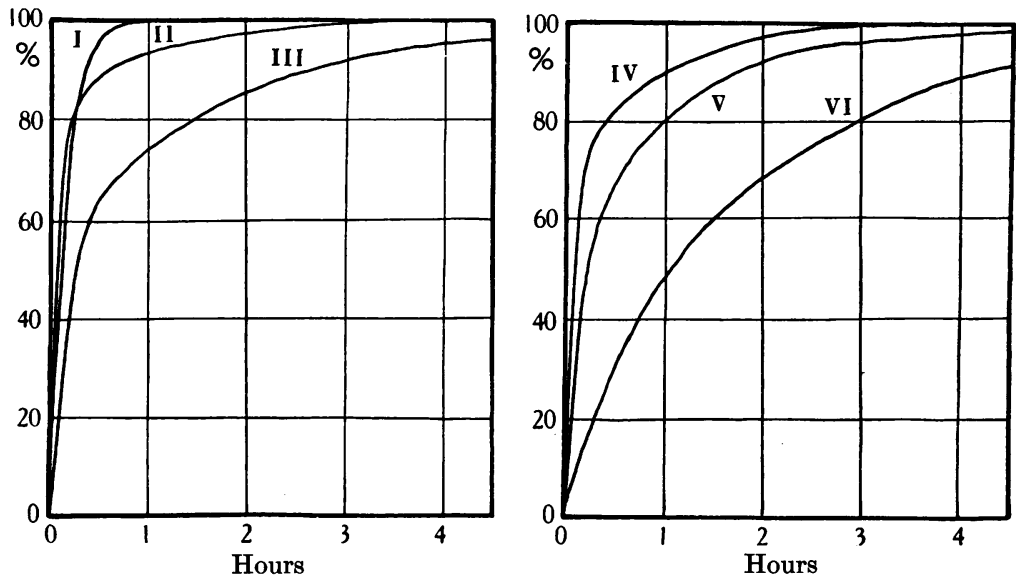

Fig. 1. Rates of absorption of amines. I, ammonia. II, isobutylamine. III, methylamine. IV, isoamylamine. V, ethylamine. VI, benzylamine. At $37^{\circ}$ in Conway apparatus.

Each Conway dish contained $2 \mathrm{ml} . \mathrm{N} / 100 \mathrm{H}_{2} \mathrm{SO}_{4}$ in the central compartment and $1 \mathrm{ml} .0 \cdot 015 \mathrm{M}$ amine hydrochloride solution $+1 \mathrm{ml}$. saturated $\mathrm{K}_{2} \mathrm{CO}_{3}$ in the outer compartment. isoButylamine and isoamylamine, although much less volatile than methylamine, were unexpectedly absorbed more quickly. The probable explanation is that the rate of absorption of the amine is determined (a) by its volatility and (b) by its solubility in aqueous solution. isoAmylamine is absorbed more rapidly than methylamine because it is less soluble in aqueous solution so that the vapour pressure of its aqueous solution is higher. 
Using this method it was found in agreement with Hare [1928] that the amount of ammonia formed when tyramine was incubated with the enzyme preparations was much less than 1 mol. per atom of oxygen taken up. This was apparently due to the further oxidation of the aldehyde by aldehyde oxidase present in the preparations, since when semicarbazide was added to act as an aldehyde fixative the ammonia formed corresponded approximately to the theoretical of $1 \mathrm{~mol}$. per atom of oxygen.

With adrenaline the amount of methylamine obtained was also much less than the theoretical calculated on the oxygen uptake unless the precaution was taken of adding $10^{-3} \mathrm{M} \mathrm{HCN}$ to inhibit autoxidation or oxidation to adrenochrome by the indophenol oxidase system [Green \& Richter, 1937]. With sympatol, which is a much more stable substrate, it could be shown that approximately the theoretical amount of methylamine was formed. The further oxidation of the aldehyde appeared to be slow in this case. The following experimental results are typical:

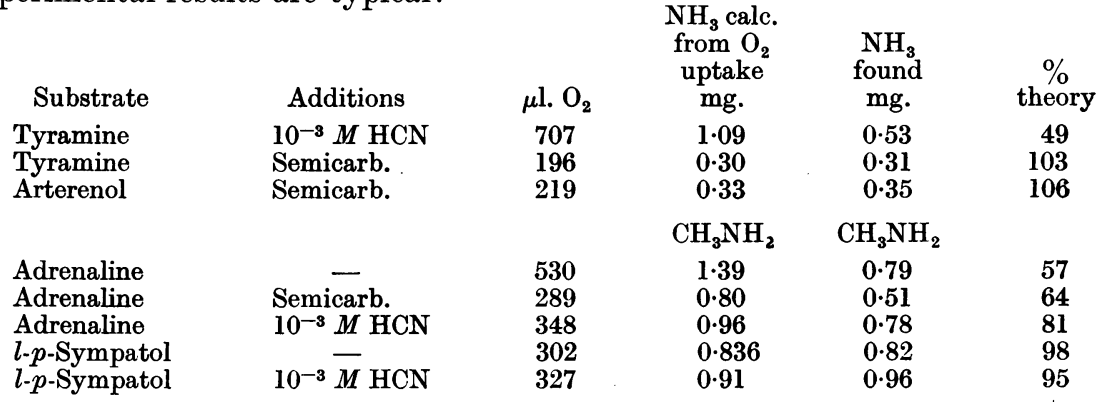

The oxidations were carried out under conditions similar to those described above, with $0.2 \mathrm{ml}$. amine hydrochloride solution and $1.8 \mathrm{ml}$. enzyme solution in each Warburg vessel. In the experiments in which semicarbazide was added $0.2 \mathrm{ml}$. of $M$ solution was used.

\section{Isolation of aldehydes}

With a further series of substrates the aldehydes formed were isolated from the reaction products as the 2:4-dinitrophenylhydrazones. For this purpose the oxidations were carried out in the presence of $M / 20$ semicarbazide to prevent the aldehydes being destroyed by further oxidation or by dismutation. The mixture of reaction products was deproteinized by boiling at $p \mathrm{H} 5 \cdot 3$, acidified with $\mathrm{HCl}$ and treated with a solution of the reagent in $2 N \mathrm{HCl}$.

Dinitrophenylhydrazones were obtained from the following substrates:

Benzylamine. The dinitrophenylhydrazone was separated by centrifuging, washed with alcohol and recrystallized twice from ethyl acetate. It separated in orange prisms, M.P. $238^{\circ}$. (Found: C, 54.2; H, $3 \cdot 7 ; \mathrm{N}, 19 \cdot 2 \% \cdot \mathrm{C}_{13} \mathrm{H}_{10} \mathrm{O}_{4} \mathrm{~N}_{4}$ requires $\mathrm{C}, 54.5 ; \mathrm{H} ; 3.5 ; \mathrm{N}, 19.6 \%$.) This agrees with the dinitrophenylhydrazone of benzaldehyde. The product obtained enzymically gave prisms showing parallel extinction, pleochroism (pale yellow-dark brown) and giving the crystal edge angle $\alpha=116^{\circ}$. The compound prepared synthetically from benzaldehyde gave M.P. $241^{\circ}$ (no depression on mixing), parallel extinction, similar pleochroism and interference and the crystal angle $\alpha=116^{\circ}$.

Phenylethylamine. The dinitrophenylhydrazone was recrystallized from $66 \%$ alcohol and agreed in properties with the derivative prepared from phenylacetaldehyde. (Found: $\mathrm{C}, 55.9 ; \mathrm{H}, 4.5 ; \mathrm{N}, 18 \cdot 3 \% \cdot \mathrm{C}_{14} \mathrm{H}_{12} \mathrm{O}_{4} \mathrm{~N}_{4}$ requires 
C, $56 \cdot 0 ; \mathrm{H}, 4 \cdot 0 ; \mathrm{N}, 18.7 \%$.) The enzymic product crystallized in pale yellow plates with a marked tendency to twinning, showing strong pleochroism, angular extinction, M.P. $118-120^{\circ}$ and with the crystal angles $\alpha=125^{\circ} ; \beta=107^{\circ}$. The derivative prepared synthetically and recrystallized from $66 \%$ alcohol under the same conditions gave similar optical properties and M.P. $120-121^{\circ}$ (no depression on mixing), and crystal angles $\alpha=125^{\circ} ; \beta=106^{\circ}$.

Tyramine. The dinitrophenylhydrazone was crystallized from benzene from which it separated in microcrystals giving M.P. $183-186^{\circ}$ (decomp.). The microanalysis agreed with the dinitrophenylhydrazone of hydroxyphenylacetaldehyde. (Found: C, 53.0; H, 3.9; N, 17.3\%. $\mathrm{C}_{14} \mathrm{H}_{12} \mathrm{O}_{5} \mathrm{~N}_{4}$ requires $\mathrm{C}, 53 \cdot 2 ; \mathrm{H}, 3 \cdot 8 ; \mathrm{N}, 17 \cdot 7 \%$.)

Adrenaline. The dinitrophenylhydrazone separated as a bright yellow precipitate on adding the reagent, but it rapidly blackened on warming or on standing and no satisfactory method could be found for purifying it. The crude substance gave on microanalysis $\mathrm{N}, 16.9 \%$. The derivative of dihydroxyphenylhydroxyacetaldehyde, $\mathrm{C}_{14} \mathrm{H}_{12} \mathrm{O}_{7} \mathrm{~N}_{4}$ requires $\mathrm{N}, 16 \cdot 6 \%$.

isoAmylamine. Pugh \& Quastel [1937] mention that the reaction products from isoamylamine give a precipitate with dinitrophenylhydrazine. The derivative was recrystallized twice from $2 \mathrm{~N} \mathrm{HCl}$ containing $25 \%$ alcohol and separated in orange plates agreeing in properties with the dinitrophenylhydrazone of $i$ sovaleraldehyde. The product obtained enzymically from isoamylamine gave M.P. $120^{\circ}$ and crystals showing strong dichroism, very brilliant interference, extinction angle $16^{\circ}$ and crystal angles $\alpha=97^{\circ} ; \beta=105^{\circ}$. The synthetic derivative gave M.P. $120^{\circ}$ (no depression on mixing), similar dichroism and interference, extinction angle $17^{\circ}$ and crystal angles $\alpha=98^{\circ} ; \beta=104^{\circ}$. (Found for enzymic product: $\mathrm{C}, 50 \cdot 7 ; \mathrm{H}, 5 \cdot 3 ; \mathrm{N}, 20 \cdot 7 \%$. $\mathrm{C}_{11} \mathrm{H}_{14} \mathrm{O}_{4} \mathrm{~N}_{4}$ requires $\mathrm{C}, 49 \cdot 6$; $\mathrm{H}, 5 \cdot 3 ; \mathrm{N}, 21 \cdot 0 \%$.)

$\mathrm{n}$-Amylamine. The dinitrophenylhydrazone crystallized from $2 \mathrm{~N} \mathrm{HCl}$ in pale yellow needles, M.P. $107^{\circ}$. This agrees with the dinitrophenylhydrazone of $n$-valeraldehyde. (Found: C, 49.1; H, 5.5; N, 20.4\%. $\mathrm{C}_{11} \mathrm{H}_{14} \mathrm{O}_{4} \mathrm{~N}_{4}$ requires $\mathrm{C}, 49 \cdot 6 ; \mathrm{H}, 5 \cdot 3 ; \mathrm{N}, 21 \cdot 0 \%$.)

Dinitrophenylhydrazones were also given by the reaction products from epinine, alkamine, arterenol, hordenine, $l$ - $p$-sympatol and isobutylamine. The formation of aldehydes could further be shown qualitatively by means of Schiff's reagent.

For a few substrates the amount of aldehyde formed was estimated quantitatively by weighing the dinitrophenylhydrazones. As was to be expected the yield of aldehyde was small in the absence of an aldehyde fixative as the free aldehydes were in most cases rapidly oxidized by the aldehyde oxidase or dismuted by the aldehyde mutase present in the enzyme preparations. The addition of $10^{-3} M \mathrm{HCN}$ served to prevent the autoxidation of the more labile substrates such as adrenaline. In the presence of $M / 20$ semicarbazide approximately the theoretical amount of aldehyde calculated from the oxygen uptake was formed.

\begin{tabular}{|c|c|c|c|c|}
\hline \multirow[b]{2}{*}{ Substrate } & \multirow[b]{2}{*}{ Additions } & \multirow[b]{2}{*}{$\begin{array}{r}\mu \mathrm{l} . \mathrm{O}_{2} \\
\text { uptake }\end{array}$} & \multicolumn{2}{|c|}{ Dinitrophenylhydrazone } \\
\hline & & & $\begin{array}{l}\text { Calculated } \\
\text { mg. }\end{array}$ & $\begin{array}{c}\text { Found } \\
\text { mg. }\end{array}$ \\
\hline isoAmylamine & - & 393 & $9 \cdot 3$ & $1 \cdot 0$ \\
\hline Tyramine & 一 & 609 & $17 \cdot 2$ & $1 \cdot 9$ \\
\hline$l$ - $p$-Sympatol & - & 222 & $6 \cdot 6$ & $0 \cdot 6$ \\
\hline isoAmylamine & Semicarb. & 402 & $9 \cdot 5$ & $6 \cdot 9$ \\
\hline Tyramine &, & 439 & $12 \cdot 4$ & $12 \cdot 9$ \\
\hline Arterenol & ", & 260 & $8 \cdot 1$ & $6 \cdot 8$ \\
\hline Epinine & , & 531 & $15 \cdot 7$ & $11 \cdot 7$ \\
\hline$l$-Adrenaline & ” & 277 & $8 \cdot 6$ & $7 \cdot 2$ \\
\hline
\end{tabular}


The oxidations were carried out in the Warburg apparatus under the conditions described above. The dinitrophenylhydrazones precipitated after deproteinizing were washed twice with $2 \mathrm{~N} \mathrm{HCl}$ before weighing.

\section{Discussion}

In the oxidation of a number of primary, secondary and tertiary amines by amine oxidase preparations it was found that in each case an aldehyde and ammonia or a lower amine was formed. These oxidative deaminations may be represented by the general equation:

$$
R . \mathrm{CH}_{2} \stackrel{+}{\mathrm{N}} \mathrm{H} R_{2}^{\prime}+\frac{1}{2} \mathrm{O}_{2} \rightarrow R . \mathrm{CHO}+\stackrel{+}{\mathrm{N}_{2}} \mathrm{H}_{2} R_{2}^{\prime}
$$

where $R^{\prime}=$ hydrogen or an alkyl group.

A number of different amine oxidases have been described in the literature (tyramine oxidase, adrenaline oxidase, aliphatic amine oxidase). The statement of Hare [1928] that tyramine oxidase does not catalyse the oxidation of adrenaline made it appear that adrenaline oxidase is distinct from tyramine oxidase, but it has not been found possible to confirm this. These oxidative deaminations are chemically very similar and Kohn (unpublished) and Blaschko et al. [1937, 3] have obtained further evidence that the three amine oxidases described are identical.

The complex relationships between oxygen uptake and ammonia formation described by Hare [1928] in the oxidation of tyramine are due to the fact that she was working with a succession of reactions involving at least three enzymesthe aldehyde oxidase and aldehyde mutase in addition to the amine oxidase. When the precaution is taken to isolate the one reaction involving the amine oxidase by using semicarbazide as an aldehyde fixative the observed relationships are simple.

Reaction mechanism. It has been shown for the substrates tyramine, adrenaline and the aliphatic amines that hydrogen peroxide is formed as a reaction product [Hare, 1928; Philpot, 1937; Pugh \& Quastel, 1937]; the hydrogen peroxide is normally destroyed by catalase present in the enzyme preparations so that it does not come into the reaction equation. The formation of hydrogen peroxide indicates that the reaction is essentially a dehydrogenation. Philpot [1937] has recently shown that other hydrogen acceptors as well as oxygen may be used in the oxidation of tyramine by tyramine oxidase. The dehydrogenation of a molecule such as that of hordenine $(\mathrm{OH}) \mathrm{C}_{6} \mathrm{H}_{4} \mathrm{CH}_{2} \mathrm{CH}_{2} \mathrm{~N}\left(\mathrm{CH}_{3}\right)_{2}$ which has no hydrogen on the nitrogen atom is difficult to represent; but these reactions proceed at neutral or even acid reactions at which only a small amount of the free base can be present, and it is therefore probably more accurate to represent the dehydrogenations as affecting the ions, which contain an additional hydrogen atom on the nitrogen atom. The oxidation of a tertiary amine such as hordenine for example could then be represented by the following equations in which the ion is dehydrogenated to give an unstable imino-derivative which is then rapidly hydrolysed to give the aldehyde and lower amine:

$$
\begin{aligned}
& R . \mathrm{CH}_{2} \stackrel{+}{\mathrm{N}}{ }_{\mathrm{H}}^{\prime}{ }_{2}+\mathrm{O}_{2} \rightarrow R . \mathrm{CH}=\stackrel{+}{\mathrm{N}} R_{2}^{\prime}+\mathrm{H}_{2} \mathrm{O}_{2} \\
& R . \mathrm{CH}=\stackrel{+}{\mathrm{N}} R^{\prime}{ }_{2}+\mathrm{H}_{2} \mathrm{O} \rightarrow R . \mathrm{CHO}+\stackrel{+}{\mathrm{N}_{2}}{ }_{2} R_{2}^{\prime} .
\end{aligned}
$$

The enzymic oxidation of amines resembles very closely the oxidation of amino-acids by the amino-acid oxidases, the mechanism of which has recently been discussed by Krebs [1936]. The fact that isopropylamine derivatives are 
not attacked by the amine oxidase although there is a hydrogen atom on the $\alpha$-carbon atom available for dehydrogenation [Blaschko et al. 1937, 2, 3] shows that the steric effect of neighbouring groups may be important in enzymes of this type and the inability of the amino-acid oxidases to deaminate $\alpha$-aminoisobutyric acid [Keilin \& Hartree, 1936] can no longer be considered a strong argument in favour of a dehydrogenation mechanism. On the other hand $N$-dialkylamino-acids should be capable of dehydrogenation if, as analogy with the amines suggests, it is the zwitterion form of the amino-acid that is attacked.

Physiological role. The amine oxidases have hitherto been considered almost exclusively in relation to the amines which are their substrates; but the present work raises the question of whether the ability of these systems to effect the biosynthesis of aldehydes may not also be of significance? The most probable function of the amine oxidase appears to be the destruction of toxic amines such as tyramine which are formed by bacteria; but it may also have a special role in connexion with the physiological inactivation of adrenaline. Weinstein \& Manning [1937] have recently found that when adrenaline is injected into rabbits an acid with similar properties to protocatechuic acid is excreted in the urine. Under these conditions the adrenaline appears to be inactivated by oxidation in the side chain of the molecule and it is therefore possible that the amine oxidase, which has been shown to catalyse the oxidation of the adrenaline in the side chain, may be partly concerned. It is clear that this type of oxidation of adrenaline is entirely different from the oxidation to adrenochrome described by Green \& Richter [1937].

\section{SUMMARY}

Adrenaline is oxidized in the same manner as other primary, secondary and tertiary amines by the amine oxidase of guinea-pig liver and intestine. The reaction products are in each case an aldehyde and ammonia or a lower amine.

Phenylethylamine, tyramine and arterenol form ammonia; adrenaline, epinine and sympatol give methylamine; alkamine gives ethylamine and hordenine gives dimethylamine.

The aldehydes and ammonia or lower amines were identified as crystalline derivatives and in a number of cases estimated quantitatively.

The quaternary salt, $N$-methylhordenine chloride, was not oxidised.

The author wishes to thank Sir F. G. Hopkins, Prof. Keilin and Dr H. Blaschko for their interest, C. H. Boehringer Sohn and I. G. Farbenindustrie A.G. for the gift of chemicals, and the Medical Research Council and Chemical Society for grants.

\section{REFERENCES}

Bernheim (1931). J. biol. Chem. 93, 299.

Blaschko, Richter \& Schlossmann $(1937,1)$. J. Physiol. 90, 1.

$-\longrightarrow(1937,2)$. J. Physiol. 89, 39 P.

$-(1937,3)$. (In the Press.)

Conway (1933). Biochem. J. 27, 419.

Green \& Richter (1937). Biochem. J. 31, 596.

Hare (1928). Biochem. J. 22, 968.

Keilin \& Hartree (1936). Proc. roy. Soc. B, 119, 114, 141.

Klein \& Steiner (1928). Jb. wiss. Bot. 68, 631.

Krebs (1936). Ann. Rev. Biochem. 5, 250.

Philpot (1937). Biochem. J. 31, 856.

Pugh \& Quastel (1937). Biochem. J. 31, 286.

Weinstein \& Manning (1937). Science, 86, 19. 